\title{
A MUDANÇA DA MONOCULTURA DO FUMO NO AGRESTE ALAGOANO: SEUS ARRANJOS PRODUTIVOS LOCAIS E OS IMPACTOS NA ESTRUTURA SOCIAL
}

\section{RESUMO}

Durante décadas a cultura do tabaco proporcionou a geração de emprego e renda, sobretudo a formação de riqueza para poucas famílias detentoras dos meios de beneficiamento e produção, na região do agreste alagoano. A agricultura familiar utilizava de suas terras para o plantio de uma única cultura agrícola, sem a possibilidade de arbitrar sobre os valores de compra e venda, uma vez que sua colheita era, geralmente, com destino a um único comprador. Com a questão de saúde pública sobre a redução do consumo de tabaco, as quedas nas vendas internas e externas, fizeram com que o governo brasileiro desenvolvesse políticas públicas voltadas para o desenvolvimento social e econômico com ênfase na diversificação da agricultura familiar, surgindo assim os arranjos produtivos locais e uma nova estrutura social.

Palavras-chave: Arranjo produtivo local; Desenvolvimento sustentável; Sociologia econômica; Estrutura social.

\begin{abstract}
For decades the tobacco culture provided the generation of employment and income, especially wealth formation for few families holders of processing facilities and production in Alagoas untamed region. Family farms used their land for planting a single crop, without the possibility to arbitrate on the purchase and sale of securities, since their harvest was usually bound to a single buyer. With the public health issue of reducing tobacco consumption, falls in domestic sales and external, caused the Brazilian government to develop public policies for social and economic development with emphasis on diversification of family farming, thus resulting arrangements productive sites and a new social structure.
\end{abstract}

Keywords: Local Productive Arrangement; Sustainable development; economic sociology; Social structure.

José Senivaldo Liberato ${ }^{1}$

\footnotetext{
${ }^{1}$ Especialização em Gestão Pública pela Universidade Federal de Alagoas - UFAL, Maceió (Brasil). Professor nas disciplinas de Empreendedorismo pela Universidade Federal de Alagoas- UFAL, Maceió (Brasil). E-mail: senivaldo@gmail.com
} 


\section{INTRODUÇÃO}

A cidade de Arapiraca, Alagoas, com população estimada em 232.671 (IBGE, 2016), sendo cerca de 32.525 habitantes na zona rural (IBGE, 2010), durante anos foi conhecida com a capital brasileira do fumo, tendo em vista o grande plantio realizado no município e em mais cinco municípios em seu entorno: Coité do Nóia (10.939 habitantes), Craíbas (24.403 habitantes), Feira Grande (22.458 habitantes), Girau do Ponciano (40.912 habitantes) e Lagoa da Canoa (18.256 habitantes). Juntos os seis municípios apresentaram um PIB de R\$ 2,274 bilhões em 2010 (MDA/SAF/DATER).

Apesar dos números demostrarem um desenvolvimento econômico regional, o Ministério de Desenvolvimento Agrário (MDA) apresentou dados de 2010 sobre a produção de fumo de 14,8 mil toneladas, sendo a cidade de Arapiraca o maior produtor de fumo com 5.115 toneladas. No entanto, se comparados diretamente com números da década de 1990, a produção caiu pela metade afetando diretamente a renda do produtor na agricultura familiar.

O desenvolvimento social e econômico da região também é afetado nas últimas décadas, ocasionando uma preocupação central do governo em buscar uma solução que possibilite a continuidade das famílias na região sem prejudicar a agricultura. A partir de então surge de forma tímida, após os anos 2000, os arranjos produtivos locais (APL's) apoiado pelo Conselho Nacional de Desenvolvimento Cientifico e Tecnológico (CNPq) e o Serviço de Apoio às Micro e Pequenas Empresas (Sebrae-AL), que possibilitou a capacitação e o acompanhamento destes arranjos ao longo dos anos, (Lustosa et al, 2011), como uma forma de garantir a continuidade da agricultura familiar com a visão de um desenvolvimento sustentável do ponto de vista socioeconômico.

Posteriormente, em 2014, a ONU (Organização da Nações Unidas) lança o ano Internacional da Agricultura Familiar, com a finalidade de fomentar o desenvolvimento socioeconômico do produtor rural e viabilizar o acesso a mercados de consumo. Esta ação teve a inciativa de agentes públicos, agentes privados, organismos internacionais e movimentos sociais ligados a agricultura familiar.

Assim, o fenômeno da mudança de cultura de tabaco para diversificação do processo produtivo torna-se um vitalizador para o desenvolvimento social do trabalhador rural entre a cidade de Arapiraca e seu entorno. Surge então uma mudança de comportamento socioeconômico na região, o que vai possibilitar o entendimento sobre a importância da 
diversificação de culturas agrícolas e a possiblidade de um desenvolvimento sustentável, social e econômico.

Através de estudos de artigos, pesquisas bibliográficas e dados socioeconômicos, busquei demonstrar o fenômeno de uma nova construção social das relações econômicas entre a agricultura familiar, o mercado e a sociedade consumidora, através da mudança no comportamento da agricultura familiar local, não sendo aqui a composição final de um estudo que irá se aprofundar através de pesquisas de campo.

Os pequenos produtores e suas famílias tornam-se mais produtivos e participativos na formação de uma estrutura social, através dos arranjos produtivos locais que passam a ser formados pelos pequenos e médios produtores que se organizaram em associações ou cooperativas para a garantia de produção da monocultura, beneficiamento e consequente venda ao mercado interno e externo.

Assim temos uma evolução do produtor rural que tendo acesso a informações sobre diversificação produtiva, tem a oportunidade de acessar outras informações sobre direitos e deveres, gerando para ele uma liberdade econômica e produtiva e consequentemente o aumento do nível socioeconômico (Sen, 2010).

\section{PRINCIPAIS CARACTERÍSTICAS DA CLASSE SOCIAL DAS FAMÍLIAS NA ZONA RURAL DA REGIÃO DE ARAPIRACA}

A população rural em 2010 foi de 32.525 habitantes este número representa uma queda de 33,63\% da população se comparado ao ano de 1980 que era de 49.004 habitantes (IBGE, 2010), conforme se observa na figura 1 , época considerada de ouro para a cultura fumageira. $\mathrm{O}$ valor do rendimento nominal mediano mensal per capita dos domicílios particulares permanentes, na zona rural segundo o IBGE, é de $\mathrm{R} \$ 185,00$ (cento e oitenta e cinco reais) enquanto que na zona urbana chega a $\mathrm{R} \$ 300,00$ (trezentos reais), uma diferença de $38,33 \%$ em relação ao rendimento rural. Com o rendimento nominal rural abaixo do urbano, pode-se entender que a maioria dos indivíduos que vivem na zona rural não possuem condições de desenvolvimento socioeconômico e sem uma política pública assertiva voltada para estes. 
Figura 1 - População Censitária Rural (habitantes)

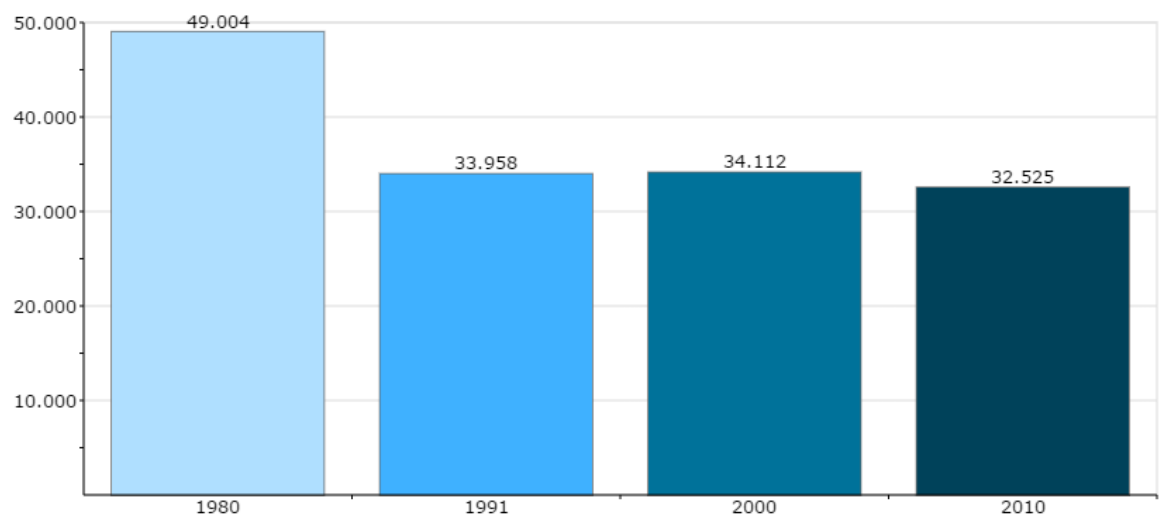

Fonte: IBGE/ALAGOAS EM DADOS - Censo demográfico 2010

Em se tratando de educação a zona rural tem, de acordo com Agencia Nacional de Telecomunicações (ANATEL), 37 escolas, sendo 36 municipais e 01 privada, para o ensino fundamental e médio. Estas escolas atendem todas as idades incluindo os programas de educação de jovens e adultos.

Dos programas sociais do governo federal a cidade de Arapiraca recebeu no exercício de 2015 R \$ 43.147.535,00 (Quarenta e três milhões, cento e quarenta e sete mil, quinhentos e trinta e cinco reais), para atendimento ao programa Bolsa Família, segundo dado do portal da transparência (2016), que atende cerca de 28.081 mil beneficiados, parte destes estão na zona rural do município.

Em relação ao programa de erradicação do trabalho infantil (PETI), ainda segundo o portal da transparência do governo federal, o município recebeu do governo federal apenas $\mathrm{R} \$$ 2.800,00 (dois mil e oitocentos reais) para o atendimento de 10 famílias. Sabe-se que a maioria das crianças até 10 anos estão trabalhando no processo da monocultura de qualquer espécie, o que caracteriza o trabalho infantil.

Os dados apresentados caracterizam uma parte importante da estrutura socioeconômica das famílias que vivem na zona rural, mais precisamente na região que compreende a cidade de Arapiraca, área que concentravam a maior produção de fumo da região do agreste alagoano. Pode-se entender que estas comunidades que vivem a décadas dependendo das monoculturas que são extraídas do solo necessitam, em parte, do apoio dos agentes públicos para que possam viabilizar o seu desenvolvimento socioeconômico. A diversificação de a monocultura surge 
como uma das maiores apostas dos agentes públicos, com a finalidade de geração de renda e desenvolvimento socioeconômico.

\section{ARRANJOS PRODUTIVOS LOCAIS, ASSOCIAÇÕES E COOPERATIVAS}

Em Alagoas são registrados 18 APL's (Arranjos produtivos locais), que compreende as diversas regiões do Estado. Destes, 06 estão ligados diretamente a agropecuária, sendo 03 deles na região do agreste que envolvem o município de Arapiraca, são eles: APL Fruticultura do Agreste, APL Horticultura do Agreste e o APL Mandioca do Agreste Alagoano (Santa Rita et al, 2015). Estes arranjos estão ligados diretamente a mudança da monocultura do tabaco, onde a transformação se deu através do apoio dos agentes de desenvolvimento socioeconômicos já citados e participação direta do produtor rural que buscava um maior ganho em sua renda familiar.

A comercialização dos produtos se dá através do próprio produtor rural, de pequenos grupos informais ou ainda de sua filiação as associações e cooperativas da região. No que compreende o município de Arapiraca são registradas, segundo dados do SEBRAE-AL através de sua Unidade de Desenvolvimento Territorial (UDT), 02 Cooperativas e 29 associações de produtores rurais, que compreende partes dos arranjos produtivos locais existentes. Essas entidades são formadas por seus associados e/ou cooperados com a finalidade de comercialização de seus produtos em grande volume, o que faz aumentar uma maior participação no mercado consumidor.

As estruturas de formação destas associações e cooperativas são organizadas em forma de diretorias com início e fim de mandato definidos em seus contratos sociais que contém todas as informações de como serão conduzidos as responsabilidades e os direitos de cada membro envolvido e de seus beneficiados. Este documento legal engessa o direito de participar dos programas governamentais como Programa Nacional de Alimentação Escolar (PNAE) do Ministério da Educação, Programa de Aquisição de Alimentos (PAA) do Ministério de Desenvolvimento Social e Combate à Fome e do Ministério de Desenvolvimento Agrário, estes são os principais programas que fomentam a agricultura familiar e consequentemente seu desenvolvimento socioeconômico visando um desenvolvimento sustentável.

As escolas públicas das Prefeituras e do Estado, efetuam as compras dos alimentos através de processo licitatório para a aquisição legal, os quais são realizados periodicamente de acordo com cada edital de cada licitação efetuada. A venda da produção também é direcionada para as empresas privadas, que compram em grandes volumes das associações e/ou 
cooperativas em comum acordo com seus associados e/ou cooperados, estes responsáveis diretos pelo fornecimento da produção.

Deve ser considerado o fato de alguns indivíduos se reunirem em pequenos grupos para de forma indireta venderem seus produtos no mercado consumidor e driblarem o processo de formalização de uma associação. Isto ocorre por questões comerciais e financeiras que fazem com que estes procurem obter benefício maior de forma individual do que em grupos de grandes participações. Apesar desta facilidade, estes não poderão participar de programas governamentais ou qualquer outro benefício social que tenha caráter público.

As questões políticas estão evidenciadas em algumas destas associações e cooperativas, quando os ocupantes de cargos de suas diretorias têm laços com políticos locais, o que de certa forma viabiliza um maior atingimento de objetivos de determinada ação por parte dos governos, seja municipal ou estadual. Mas, em contrapartida torna-se fator de constrangimento para alguns participantes que, em alguns momentos, divergem de seus ideais políticos ou de ações especificas, direcionando assim a formação da estrutura social dos envolvidos em todo o processo.

\section{AS ESTRUTURAS SOCIAIS E O DESENVOLVIMENTO SOCIOECONÔMICO}

Com a organização dos produtores em associações, cooperativas ou ainda em pequenos grupos informais, temos a caracterização da formação de uma nova estrutura social do ponto de vista da sociologia econômica (Steiner, 2006) em comparação com o que havia nas últimas décadas. Esse fenômeno de acesso a informação e tecnologia, proporcionado pelos agentes públicos, para novos processos na monocultura diversificada possibilita um questionamento a respeito de como a interação entre mercado consumidor e produtor rural se dá e como essa continuidade de relações de mantém. Percebe-se que com o avanço do arranjo produtivo local, como o da horticultura por exemplo, há uma construção de um novo modelo de mercado econômico, antes isolado, possibilitando um desenvolvimento social para as famílias produtoras. Sem a necessidade direta de um atravessador, o produtor rural pode vender sua produção diretamente nas feiras livres ou à minimercados e/ou supermercados da região, possibilitando assim um maior rendimento financeiro e uma interação direta com uma nova realidade de mercado.

Assim, nasce através da interação desta estrutura social, formal ou informal, uma rede de atores locais (Julien, 2010) que possibilitam uma clara comunicação e atuação entre mercado 
e os demais segmentos da sociedade o que possibilita o empreendedorismo regional através da economia do conhecimento, melhorando a produtividade, qualidade de vida e a aplicação do desenvolvimento sustentável.

Um exemplo desta dinâmica de desenvolvimento da estrutura social se dá pelo alcance de quase $70 \%$ de cobertura na região do agreste alagoano do programa de arranjo produtivo local (PAPL) da monocultura da mandioca, ou mandiocultura, que envolve mais de 30 mil agricultores familiares alagoanos. A produção estimada no segundo semestre de 2014, segundo dados do Programa de Arranjo Produtivo Local (PAPL), Secretária de Desenvolvimento Econômico do Estado de Alagoas (SEPLANDE-AL) e Sebrae-AL, 80\% das raízes produzidas foram comercializadas por intermediários para outros estados, deixando claro a interferência de agentes externos dentro da estrutura social. Este arranjo produtivo se estende para outros municípios alagoanos como Campo Grande, Coité do Nóia, Craíbas, Feira Grande, Girau do Ponciano, Igaci, Lagoa da Canoa, Limoeiro de Anadia, São Sebastião Taquarana, compreendendo a região direta da monocultura do tabaco, fazendo parte também deste arranjo produtivo local os municípios de Junqueiro, Olho D’Água Grande, Palmeira dos Índios e Teotônio Vilela, compreendendo assim uma nova estrutura social.

É evidente que as regras e os recursos (Giddens, 2009), não podem ser vistas de forma separada na construção, ainda contínua, das estruturas sociais existentes. A necessidade de uma análise aprofundada sobre o contexto que envolve todos os atores locais é imprescindível, visto que a evolução desta região ainda tem espaço para sua continuidade.

O impacto social causado por esta mudança dos últimos anos é percebido na região como forma de crescimento da zona urbana, bem como a melhoria na qualidade de vida e moradia na zona rural. O acesso à educação é uma variável indiscutível que colabora diretamente neste processo de estruturação socioeconômico, visto que os indivíduos são propagadores cognoscitivos, além de estarem interagindo em ambientes diferentes de sua rede de atuação. A reestruturação produtiva em todo o Estado de Alagoas (Lira, 2014), sobretudo no agreste, possibilita um repensar sobre as questões socioeconômicas e como os atores sociais envolvidos cooperarão com a continuidade para o processo de tecnologia e inovação para a agricultura familiar e quais políticas públicas serão de fato efetivas para este desenvolvimento regional. 


\section{CONSIDERAÇÕES FINAIS}

Não está sendo considerado neste trabalho o valor (preço) da mercadoria ou seu valor de uso. O que se pretende levar em consideração, além da força de trabalho e o contexto em que ela é desenvolvida e sua estrutura social pelos fatos apresentados, é que os indivíduos estão expostos de forma direta ou indiretamente, dependendo ou não de suas opiniões e necessidades, a uma estrutura de certa forma ainda deficiente em atingir o objetivo, devido aos métodos dos sistemas e suas regras e propósitos específicos.

O resultado de todo o processo produtivo que envolvem as famílias na agricultura da região do agreste alagoano, em cena o município de Arapiraca com sua zona rural farta de informações, será a verificação de uma nova estrutura social e todos os efeitos gerados por esta nos últimos anos. Percebe-se ainda, que no momento em que os indivíduos que ocupam determinados papéis sociais sejam nas associações e/ou cooperativas, retém uma certa individualização no desempenho de seu papel social junto com os produtores, sejam estes de interesse direto, de determinados indivíduos ou ainda de interesse político.

O bem coletivo de uma sociedade deve ser levado em consideração. No entanto, percebe-se que na prática este direcionamento fica em segundo plano, por razões desconhecidas ou por razões expostas. A constituição desta sociedade rural, deverá ser motivo de estudo aprofundado, onde deverão ser buscadas informações que possibilitem um maior entendimento ou questionamento aprimorado sobre seus efeitos, comportamentos e atitudes no meio social.

As estruturas ou sistemas existentes, e qualificados, podem não ser o suficiente para fomentar a proposta original de mobilizar e desenvolver uma sociedade, no caso rural, que viabilize seu próprio desenvolvimento socioeconômico de forma independente, uma vez que sua intenção de origem tenha sido entendida de forma diferente e/ou em alguns casos pelo anseio de mobilizar todos de forma rápida ou ainda pelos direcionamentos individuais externos. A ideia de legitimação e dominação na estrutura social deve ser levado em conta no momento de um aprofundamento sobre o tema, considerando as dimensões envolvidas e seus atores e objetos de estudo.

As regras que direcionam todo o processo estrutural da formação desta sociedade merecem também um estudo minucioso que busquem informações que possam direcionar questionamentos e pesquisas para o entendimento onde qual será a direção que este grupo singular irá trilhar pelas próximas décadas. Não se pode desconsiderar as questões de fomento 
governamental e seus programas de distribuição de renda ou qualquer outro que possibilite a inclusão ou continuidade de sua formação social.

Busca-se, por fim, o entendimento da consciência coletiva para o desenvolvimento de uma estrutura social, de forma equilibrada, com sustentabilidade e aplicabilidade por qualquer indivíduo, independentemente de sua geração ou qualificação profissional. Torna-se um agente reflexivo será a questão que deverá ser levantada para que os membros desta sociedade possam entender a finalidade do convívio social e seu desenvolvimento em todas as esferas.

A forma de estruturação social e sua padronização, merece destaque na busca de um novo comportamento socioeconômico através da mudança do processo produtivo, analisando as dimensões sintagmáticas, sua padronizações e relações sociais (Giddens, 2013), os processos produtivos e as tecnologias envolvidas e o tempo e espaço de suas realizações. Desta forma poderemos compreender como se formam as famílias e a sociedade envolvidas nestes arranjos produtivos e na mudança na monocultura da região do agreste alagoano em busca do desenvolvimento sustentável e socioeconômico.

\section{REFERÊNCIAS BIBLIOGRÁFICAS}

Alagoas em Dados. (2013). Sistema de Informações Municipais. Disponível em http://geo.seplande.al.gov.br/geoweb/wizard/php/frmConsultaDefVariaveis.php.

Giddens, Anthony. (2013). A Constituição da Sociedade. São Paulo. Martins Fontes. $3^{\mathrm{a}}$ Ed. $2^{\mathrm{a}}$ tiragem.

Instituto Brasileiro de Geografia e Estatística. (2016), População Alagoas, Arapiraca, Disponível em http://cidades.ibge.gov.br/xtras/perfil.php?codmun=270030

Julien, Pierre-André. (2010). Empreendedorismo regional e a economia do conhecimento. São Paulo. Saraiva.

Lira, S.; org. Alagoas: 2000-2013. (2014) São Paulo. Fundação Perseu Abramo.

Lustosa, M. C. J.; Rosário, F. J. P. (Orgs). (2011). Desenvolvimento Local em Regiões Periféricas: A política dos arranjos produtivos em Alagoas. Maceió. Edufal.

Portal da Transparência. (2016). Transferência de recursos por município e ação governamental. $\quad$ Disponível em http://www.portaldatransparencia.gov.br/PortalTransparenciaListaAcoes.asp?Exercicio=2015 $\&$ SelecaoUF $=1 \&$ SiglaUF $=$ AL $\&$ CodMun $=2705 \&$ Pagina $=3$

Santa Rita, Luciana Peixoto. (Org). (2015). Indústria, tecnologia e aglomerações produtivas: uma perspectiva regional. Maceió. Edufal.

Sen, A. (2010). Desenvolvimento como Liberdade. São Paulo: Companhia das Letras. 
Silva, J. R. Pauferro; LEITE, A.M. Araújo. (2009). Organização e desenvolvimento territorial da atividade agrícola em Alagoas. XIX Encontro Nacional de Geografia Agrária, São Paulo.

Steiner, Philipe. (2006). A sociologia econômica. São Paulo. Atlas.

Rosário, F.J.P. (Org). (2015). Desenvolvimento e mercados no nordeste brasileiro: estudos e ensaios. Maceió. Edufal. 